\title{
A Survey of SSR Mechanism and Application
}

\author{
Muhammed Kürşad Uçar \\ SAKARYA UNIVERSITY \\ Faculty of Engineering, Electrical \\ and Electronics Engineering \\ Department
}

\author{
Mehmet Recep Bozkurt \\ SAKARYA UNIVERSITY \\ Faculty of Engineering, Electrical \\ and Electronics Engineering \\ Department
}

\author{
Ferda Bozkurt \\ SAKARYA UNIVERSITY \\ Faculty of Engineering, Electrical \\ and Electronics Engineering \\ Department
}

\begin{abstract}
This article aims to introduce readers to a recent research topic, sympathetic skin response (SSR). The article provides information on the historical development of sympathetic response since the late 19th century. The article also includes information on the identification of naturally existed amplitude and latency values and classification based on these values, international measurement techniques with the studies conducted within the last hundred years, the factors effecting these measurements according to the studies conducted, and criteria used in the evaluation of the data obtained. In addition, information is given about the studies that have been made.
\end{abstract}

\section{Keywords}

Skin Response, Sympathetic skin response, electrodermal activity

\section{INTRODUCTION}

Today it is clear that technology has accounted for the greatest changes in medicine. Obviously the existence of technology in medicine has been the sole supporter. Thanks to advances in the field of technology, numerous methods that can be used for diagnosis and treatment of disease was discovered and developed. One of these methods is measurement of the response of the human body against diseases. These measurements may be carried out to the diagnosis of the disease.

The human body has a very sensitive structure. Any change in the body results in an immediate response. Skin resistance in human body varies depending on a number of psychological and physiological reasons [1], and since the content of the skin shows differences between the regions of the body, the skin resistance may vary by region. For example, someone who is allergic to pollens may experience itching and erythema of the skin when exposed to pollens. This shows the response of the human body and is almost a precursor of an unusual situation. In the same way, the changes occurring in the body due to psychological or physiological causes increase or decrease the resistance of human skin. If there is any damaged nerve in the body, an excessive increase is found in skin resistance values close to that area. For this reason, in the medical world, measurement of skin resistance is considered as a method for early diagnosis of diseases [1,2].

\section{SYMPATHETIC SKIN RESPONSE}

Sympathetic skin response (SSR) is an instant, but not permanent electrodermal activity (EDA) of the skin in response to the stimulation of the skin with any internal or external stimuli.

Electrodermal activity of the skin against different stimuli has been known since the end of the 19th century. It was first described by Tarchanoff in 1890 [3]. However, it was first expressed by Vigouroux in 1879. Then the physiological and psychological researches began to be conducted [4,5] Although it has been known for long years that the skin is electrically active, the relationship between the SSR and sweat glands in the skin was introduced by Tarchanoff[6]. Vergaut has defined psychogalvanic reflex phenomenon defined, which in turn constitutes the basis of SSR [7]. The first clinical application in humans has been in the 1960, and Goadby and Downman in1973 and Shahani et al in 1984 studied SSR in somedysautonomic patient groups [7]. Interest in this area was increased with the development of noninvasive methods by Shahani[1984] and Knezevic[1985][8,9]. The recording application of SSR in electrophysiology lab was first conducted by Shahani in 1984 and then by Knezevic in $1985[8,9]$.

By this time, electrodermal activity was given many names. Although there was no consensus in the early days, it was termed as galvanic skin response or psychogalvanic. In the 1970 s and 1980s, it was termed as endosomatic when this response was recorded as electrical skin potentials, and as exosomatic when this response was recoded as a change in skin resistance against externally applied electrical current [3]. In the literature, it has been termed as electrodermal activity [4], electrodermal response [5], psychogalvanic reflex [10], galvanic skin response [36], peripheral autonomic surface potential [8], and sympathetic skin response most commonly [9]. In 1984, Shahani first used the name "sympathetic skin response" [9].

Two different forms of electrodermal activity are known in the skin. In the first, a surface electrode is placed on two different points of the skin to be measured, in which palms and soles of the feet which have the minimum skin resistance are generally preferred in these conventional investigations. Then, an electrical current is provided through the surface by means of an external source, and skin resistance is calculated with the measured values. 


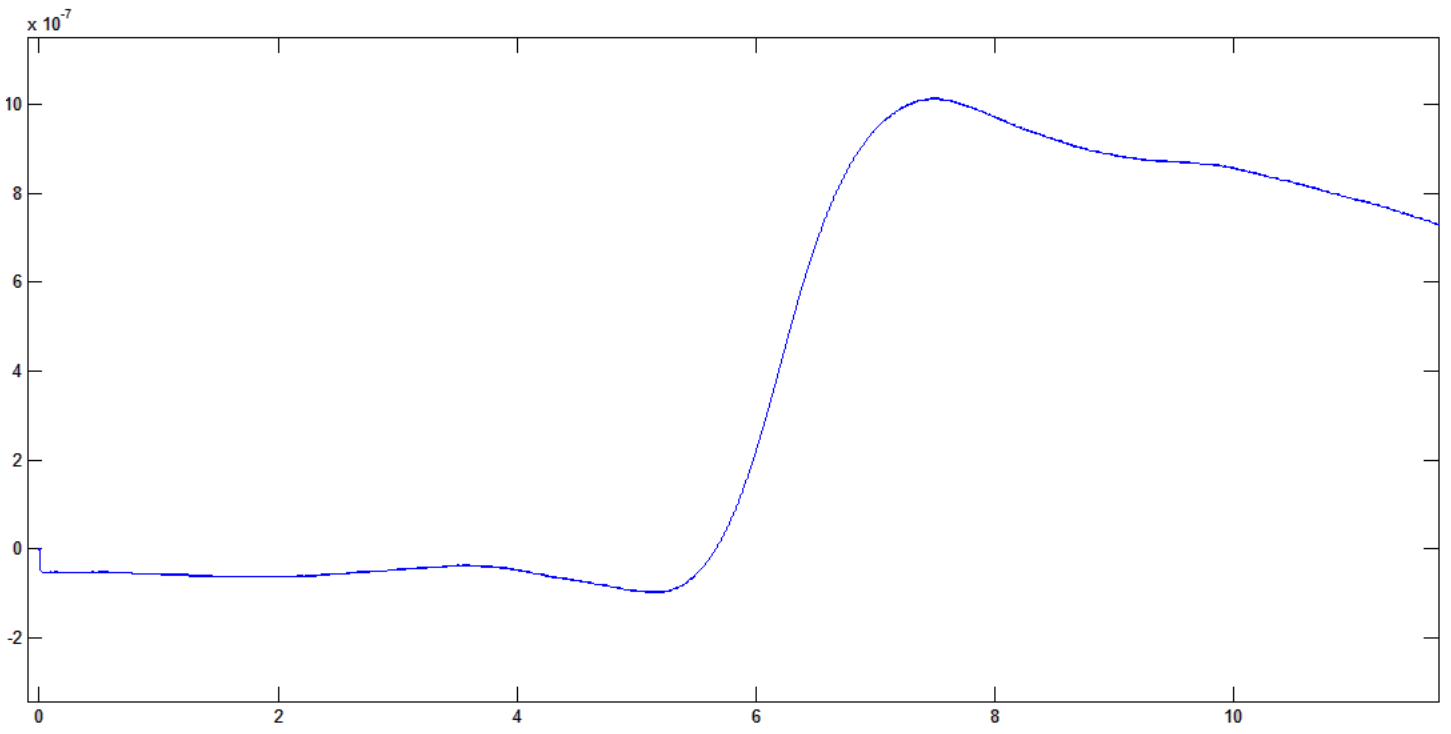

Fig 1: Normal SSR Example (Volt/sec)

In the second, the skin potential that is induced by psychological or physiological stimuli is recorded with the aid of an oscilloscope. These recorded data are called as sympathetic skin response. This is a method frequently used for the diagnosis of diseases. Since the skin is associated with autonomic nervous system, its resistance varies with the involuntary activities of the body. For example, the opening of the eyes, coughing, voice alert and sudden changes directly affect the resistance of the skin. Accordingly, they directly affect the sympathetic skin response (SSR). Sympathetic skin response (SSR) can be detected with pain, touch and changes in temperature [7].

\section{THE STRUCTURE OF SYMPATHETIC SKIN RESPONSE}

\subsection{Latency and amplitude}

Latency is the time from the stimuli to the first deviation. Amplitude is the voltage change on the surface of the skin due to the movement of ions in the sweat glands $[11,12,13]$. Latency is measured in milliseconds (ms), whereas the amplitude is measured in microvolts $(\mu \mathrm{V})$.

Aramaki have reported the normal latency for arms as 1150 to 2570 milliseconds (ms) and the amplitude as 1500 to 2200 microvolts $(\mu \mathrm{V})[14]$. Legs have higher latency values and lower amplitude values.

SSR is a sign usually beginning with a negative phase and continuing in a positive phase. The sign's wave structure may be different. In particular, it is very difficult to standardize the amplitude values because it is highly variable even in normal people [13]. Most authors recommend taking the average of the highest 5 to 6 amplitude and latency values $[8,9,15]$.

In healthy individuals, the latency values from the hands are relatively lower than the latency values from the legs $[9,16,17]$. The amplitude values of the hands are relatively higher than that of the legs.

\subsection{Shape of the response}

Depending on their maximumamplitude and their wavepolarity there are 2 types of wave forms called P-type and N-type. P-wave form is usually available in healthy individuals $[18,19]$. The figureshows theP and $\mathrm{N}$ typewave forms of the sympathetic skinresponse[3].

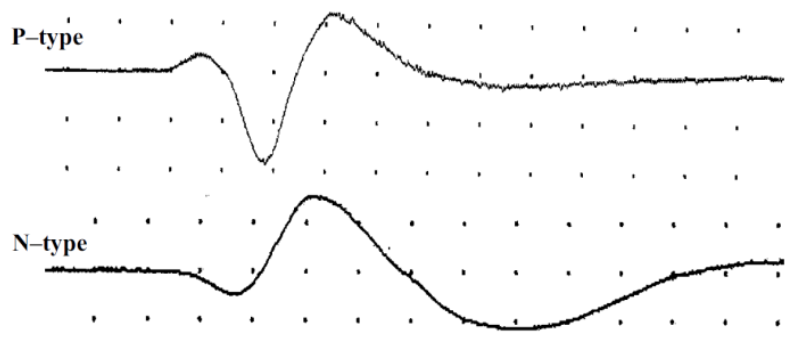

Fig 2: $\mathrm{P}$ and $\mathrm{N}$ type sympathetic skin response waveforms [3]

Sympathetic skin response usually consists of the negative and positive phases. The source of the negative phase is sweat glands. The source of the positive phase has not exactly been detected. In the recordings obtained by microelectrodes placed in the cavity of sweat glands, negative responses with no accompanying positive phase were obtained. This supports the thesis that the sweat glands form the negative phase of the response [20].

The response is generally biphasic or triphasic in the hands, biphasic in the legs, and rarely monophasic. Over $40 \%$ of healthy adults, in the recordings from the hands, a negative wave with a lower amplitude value is followed by a positive wave with a higher amplitude value. Initially, a negative wave with a lower amplitude value or rarely a positive wave can be seen [20].

\section{MEASUREMENT TECHNIQUES OF SYMPATHETIC SKIN RESPONSE}

SSR can be recorded simply and fast with the classic EMG device in many electrophysiology laboratories. Many methods have been defined and all extremities can be analyzed [21]. In studies in the literature, the measurements have been performed in the sites, such as perineum, genitalia, middle finger, thumb and toes $[22,23,24]$. The active electrodes are placed on the palmar surface of the hands and sole of the feet, whereas reference electrodes are placed on the back of the body $[20,21]$. In general, the palms and the soles which have 
the lowest skin resistance are preferred for recording. Ag$\mathrm{AgCl}$ electrodes are used during recording.

Stimulation may be in many different ways. These include coughing, deep breathing, high volume, electrical, magnetic or laser stimulation through peripheral nerves, tapping on the skin, cold pressure test, subcutaneous injection, or light. However, the most commonly applied is electrical stimulation of a peripheral nerve. Stimulation generally locates in the opposite half of the recorded region. Electrical stimulation is randomly applied in the form of a single stimulus at 0.1 to 0.5 ms duration. In order to avoid the adaptation to stimuli, the duration between the two stimuli should be at least 30 to 60 seconds [20]. Total duration of the test should not exceed 15 minutes [25]. The stimulus intensity is normally between $10-$ $30 \mathrm{~mA}$, but it should be applied based on patients' tolerance to the stimulus intensity. In order to avoid adaptation to the stimulus average latency response should not be applied because the latency response might be different from another response [20]. The low-frequency filter should be $0.5 \mathrm{~Hz}$ or below, the higher frequency filter must be approximately $2000 \mathrm{~Hz}$ [21]. Failure to measure SSR may be due to the central sympathetic system [26].

In the studies conducted, it has been observed that SSR showed interpersonal differences or even intraindividual differences. Therefore, clinically important point is the presence or absence of the response $[13,20,27]$. No response is considered if there is no response after ten consecutive stimuli [14]. No response in one of the arms and legs or an amplitude difference of $50 \%$ between the right and left sides indicate an abnormal result [28].

In particular, amplitude can easily be affected by many internal or external factors [eg, emotional status, breathing and environmental features]. It is not a very reliable parameter for determining SSR at sympathetic activity level. Studies showed that SSR gives intersubject differences, or even intrasubject differences all the time $[11,13,27]$.

Resendeet $\mathrm{al}^{29}$ reported that swallowing, winking, joint movements, biting, light stimulus, acoustic stimulus, and sphincter muscle contraction are capable of inducing SSR [29].

\section{FACTORS AFFECTING SYMPATHETIC SKIN RESPONSE}

Many factors should be considered in assessing the sympathetic skin response. Otherwise, our efforts can go wasted because of a small mistake.

\subsection{Adaptation}

The amplitude of SSR has been observed to decrease with repeated stimuli [3]. Aramaki reported that a significant decrease occurred in the amplitude after three consecutive stimulations [3,14]. In Ellie et al.'s study, the amplitude value of SSR has been found to equal to $50 \%$ of the baseline value after the first 60 minutes. A significant reduction occurs in the amplitude after a 15 to 20 minute study [3,14]. In addition, it was determined that stimulations at short intervals lead to adaptation to stimulus $[3,14]$. Therefore, it is recommended to give stimulations at an average of 15 minutes and in an irregular manner, maintaining a minimum of 30 to 60 second intervals.

\subsection{Gender, Age, Weight}

The amplitude of SSR is based on age [20]. There are different opinions regarding the effect of age on SSR. In the study of 100 healthy individuals, Drory et al. reported very low amplitude values in the elderly. But they did not observed any change in latency values [30]. Although amplitude differences were observed in the study of Drory et al., Baba et al.in their study on 45 healthy individuals did not observe a significant change in amplitude values [31].

The presence or absence of the signal in SSR is observed according to the evaluation criteria. In Drory et al.'s study on healthy individuals over the age of 60 , they observed $50 \%$ and around $70 \%$ losses in SSR in data from the arms and legs. In a group of healthy subjects under the age of 60 SSR was $100 \%$ present. However, Braune et al marked that SSR was $100 \%$ present in a group of healthy subjects above the age of 60 also.

\subsection{Stimulation Methods}

A commonly used form of stimulation is to apply a snapping sound of 65 to $105 \mathrm{~dB}$ through a pair of headphones [32,33], or a snapping sound along with an electrical stimulation [34].

Ellie et al. could not detect a significant change in SSR amplitude and latency values obtained by acoustic stimulation and electrical stimulation of the median nerve contralateral [16,35], which was also observed by Satchell and Seers.

The sympathetic skin response is thought to also be obtained by direct magnetic stimulation of peripheral nerves and brain [36-40]. In addition, in rare cases, startling stimuli [41], laser stimulation of the skin $[42,43]$, and stimulation of the rib cage with percussion [15] have also been reported.

In addition, Denišlič and Meh did not observe a significant change in amplitude and latency values of SSR through electrical stimulation and the mechanical stimulation via the percussion of the rib cage. Shahani et al. observed no significant difference in the amplitude values between deep breathing stimulation and electrical stimulation of peripheral nerve [9]. SSR shows higher correlation with the level of individual attention. Deep breathing or multiple simultaneous stimulations [electric or acoustic] can increase the amplitude of the response [25].

The pattern and latency of the response are not significantly affected by the alteration of the type and location of the stimulation [20]. However, latency can vary according to site of recording. For example, the latency from the base of the foot is longer than that from the arms $[14,27,28]$. Circadian rhythms have been reported to be effective on the latency of SSR. The mean latency in the morning is shorter than that obtained in the midday and evening [20].

SSR obtained from the foot is usually biphasic. The amplitude of the response from the hand is usually higher than that from the foot. Amplitude is variable and may reach a few millivolts, and if the stimulation is given at frequent intervals for SSR, amplitude is reduced but the latency is not changed $[9,16,44,45]$.

The use of antihypertensive and anticholinergic drugs, ambient temperature, stimulation frequency, the fact that the amount of sweating can show individual differences and can be affected by blood electrolytes can give a significant variability to latency and amplitude values and negatively affect the display of abnormalities [11].

\subsection{Body Temperature}

SSR potentials is affected by environmental temperature, skin potential level, the skin temperature, the stimulation severity, 
mental state, a sudden stimulus, and adaptation due to repeated stimulations.

SSR latency and amplitude is in a linear relationship with the body temperature. For example, one-degree increase in the skin temperature has been observed to provide $8.5 \%$ increase in amplitude and no change in latency [11].

It is recommended to wait for 15 to 20 minutes at fixed room temperature before measuring. Local heating of the limbs is not recommended, otherwise, can lead to depolarization of sweat glands, and this increases SSR amplitude value $[16,46]$.

There are many studies on the effect of temperature on the latency and amplitude, showing that a decrease in skin temperature reduces latency and amplitude of SSR. Therefore, SSR studies should be performed with a person in the supine position on room temperature of 22 to $24^{\circ} \mathrm{C}$ and at a dim and quiet room, when the person is loose and lying awake [20,25,47-49].

\section{EVALUATION PARAMETERS OF THE SYMPATHETIC SKIN RESPONSE}

There is no consensus on the things to do during recording and evaluation of the SSR in the literature. There are two different approaches. The first is that the absence of SSR sign as a pathological indicator is regarded as a qualitative observation [50-52]. The other is the quantitative assessment. Another group of authors adopted only the latency measurements as there are very few latency changes [15,50]. Another group has chosen to measure only the amplitude. Because they consider that the first slow deviation after the onset of the sign could not exactly be determined [31].

Some authors have taken the average of the response $[8,9,15]$. However, the average of the response varies by SRR pattern and adaptations [31]. Some authors consider the absolute value of the latency and amplitude values of the response to the first stimulation on the basis of their experience. Others consider the absolute values of the highest amplitude and lowest latency values $[53,54]$.

In addition, some author groups have chosen to take the average of several consecutive measurements [55].

\section{CLINICAL APPLICATIONS OF SYMPATHETIC SKIN RESPONSE}

Alteration of the electrical activity of the skin was first observed in 1888 by a French neurologist Charles Fere[56]. Charles Fere applied a direct current [DC] to the skin and recorded the resulting electrical changes. This application is found to cause electrode polarization in a short time. An alternating current $[\mathrm{AC}]$ source has been used to minimize the polarization effect. The polarization electrodes still occurs, but this adverse effect has been reduced further by using $\mathrm{Ag} / \mathrm{AgCl}$ electrodes and appropriate electrolytes [57].

The procedure of Fere includes the changes in EDA that passes between two small electrodes on the skin surface and is observed when the individual undergoes various stimulations. Increase in skin conductance is measured with the aid of a galvanometer. This phenomenon is first termed as psychogalvanic reflex [PGR], and later named as GSR [galvanic skin response].

Standardization studies about the method and technique were initiated by Edelberg and Venables in 1967 [58]. Psychophysiological variables are of great importance in the early 1970s. Psychophysiology research communities developed EDA measurement standards in these years and published them in the early 1980s. Some of these researchers are Fowles, Likeend, Venables and Christe[59]. Today, electrodermal activity (EDA) is a method used in many fields, especially in psychophysiology and neuropsychology. Electrodermal activity has been the subject of parapsychological researches in an increasing manner [60].

Clinical applications in humans began in the 1960s. Goadby and Downman in1973 and Shahani et al in 1984 studied SSR in some dysautonomic patient groups [7].

There are very few studies on sympathetic skin responses of facial region [61], a study on sympathetic skin responses of the face and neck in normal subjects was recently published by Yildiz SK et al [62].

Chest breathing is also in correlation with the EDA system. Whether there is an effect of EDA caused by the course of sudden respiratory irregularity, and the effect size was observed to fall between 30 to $77 \%$ of the original values. The effect of EDA has been reported to be very close to that of the pulmonary system [60].

In Ozkan et al.'s study conducted in 2011 intending to increase the accuracy of diagnosis by supporting laboratory tests used in the diagnosis of fibromyalgia syndrome with sympathetic skin response parameters, success rate of artificial neural networks [ANN] analysis was $68.2 \%$ only with laboratory test data, $54.5 \%$ in the simulation performed by supporting only with SSR parameters, and $86.4 \%$ in the simulation performed by supporting laboratory test data with SSR parameters. As a result, it has been observed that SSR alone cannot be a differentiating parameter, and that the diagnostic accuracy of $86.4 \%$ obtained via ANN analysis by supporting laboratory test data with SSR parameters indicates that SSR increases the diagnostic accuracy as a supporting factor and provides more meaningful results [63]

In a study conducted in Turkey, SSR recordings of cases with reflex sympathetic dystrophy syndrome [RSDS] revealed an increase in the amplitude and a decrease in the latency in the involved extremity compared with the healthy side. In the same study, reduction of the amplitude and prolongation of latency were detected with stellate-ganglion block using diadynamic current, and it was concluded that SSR can be used to assess sympathetic dysfunction, to diagnose RSDS and to measure whether sympathetic hyperactivity responds to the sympathetic blockage [64].

In 2011, Milanlioğlu et al reached the following conclusion in their study comparing the sympathetic nervous system profile of migraine patients in headache-free period and control subjects using somatic skin response. Migraines have a longer latency of sympathetic skin response in headache-free period, which reveals that migraine patients have sympathetic hypofunction compared with the controls [55].

In 2005, the results of Aygul et al in their study aimed to investigate whether differences exist in latency, amplitude and habituation between different waveforms in healthy individuals suggest that waveform patterns should be taken into consideration for the definition of normal ranges of the amplitudes and latency of SSRs. Again, it was recommended to the equation for the distribution of waveform patterns of SSRs in patients and controls before comparing amplitude and latency values [18].

Dogramaci et al in their study evaluating the sympathetic nervous system disorder in vitiligo patients using sympathetic 
skin response have found that vitiligo has no effect on the sympathetic skin response [65].

Cakir et al. in their study have evaluated the sympathetic skin response [SSR] and electroneuromyographic analysis of Fwave in patients with fibromyalgia in order to determine whether fibromyalgia syndrome [FMS] has autonomic dysfunction or not. When compared with the controls, fibromyalgia patients were found to have higher SSR amplitude values and lower latency values on both sides $(\mathrm{p}<0.05)$. In conclusion, an alteration indicating an autonomic dysfunction was found in sympathetic nervous system of patients with fibromyalgia [66].

\section{RESULTS}

In recent years intensive studies are being performed on the sympatheticskin response[SSR] and strikingimprovements have been made. This article was focused on sympatheticskin responseand information on SSR's historical development was given. Measurement techniques of SSR, the structure, factors that effect SSR, the information on the application areas and clinical practices was also given. All these studies show that diagnosis of the autonomic nervous system diseases with the help of SSR is a good study topic and have bright future.

\section{CONCLUSION}

DuetotheTherapiddevelopment of medicalelectronics , biologicalsigns becomemoremeaningfulandhavebecomethesteps of diagnosingillnesses. Thisarticle is consideredtobenefit on future SSR studiestechnically. Hopefullythegivendetailedinformationabou $\mathrm{t}$ SSR is used in futurediscoveriessuch as measurementtechniques, connectiontypes, etc. It can be a source of informationthatmay be needed. Inthis sense, thearticleshedlight on theinformationdescribed in thestudy.

\section{REFERENCES}

[1] Gülhan $\mathrm{H}$, deridirencideğerlerininHastalıklardaöntanıaracıolarakkull anılması. YüksekLisansTezi - 2009. Turkish.

[2] Çetinyalçin I.CiltRezistansinaTesir MuhtelifFaktörler, PeriferikSinirHastaliklarindaCiltRezistansiveEhemmiyeti UzmanlikTezi, I.Ü. Cerrahpasa Tip FakültesiKütüphanesi, No: 538. Turkish

[3] Kucera P, Goldenberg Z, Kurca E. Sympathetic skin response: review of the method and its clinical use. BratislLekListy 2004; 105 [3]: 108-116.

[4] Verghese A. Some observations on psychogalvanic reflex. Brij J Psychiat 1968; 114: 639-642.

[5] Christie MJ. Elekctrodermal activity in the 1980s: a review. J Roy Soc Med 1981; 74; 616-622.

[6] Guida A. A new method of simultaneous recording of two effects of the psychogalvanic reflex [Tarchanoff effect and Fere effect]RivPatolClin. 1957 Jun;12[6]:3031.

[7] Ertekin C. Santralveperiferik EMG Otonomsinirsistemi. 2006:884-909. Turkish.

[8] Knezevic W, Bajada S. Peripheral autonomic surface potential: a quantitative technique for recording sympathetic conduction in man. J NeurolSci 1985; 67: 239-251.

[9] Shahani BT, Halperin JJ, BouluPh, Cohen J. Sympathetic skin response - a method of assessing unmyelinated axon dysfunction in peripheral neuropaties. J NeurolNeurosurg Psychiatry 1984; 47: 536-542.
[10] Lader MH, Montagu JD. The psychogalvanic reflex: a pharmacologic study of peripheral machanism. J NeurolNeurosurg Psychiatry 1962; 25: 126-133.

[11] Arunodaya GR, Taly AB. Sympathetic Skin Response: A Decade Later, Journal of the Neurological Sciences, 129: 81-89, 1995.

[12] Cariga P, Catley M, Mathias CJ, Savic G Frankel HL, Ellaway PH.Organisation of the Sympathetic Skin Response in Spinal Cord Injury. J. Neurol. Neurosurg. Psychiatry, 72:356-360, 2002.

[13] Selçuk B, Atlı D, Kurtaran A, İnanır M, Akyüz M.Serebrovasküler Olay SonrasıHemiplejiGelişenHastalardaSempatikDeriYanıtla rı. TürkFiz. Tip ve Rehab. Derg., 49[5]:18-23, 2003. Turkish.

[14] Aramaki S, KiraY, Hirasawa Y. A Study of the normal values and habituation phenomenon of sympathetic skin response. Am. J. Phys. Med. Rehabil., 76: 2-7, 1997.

[15] Denišlič M, Meh D. Sympathetic skin response in Parkinsonian patients. ElectromyogrclinNeurophysiol 1996; 36: 231-235.

[16] Elie B, Guiheneuc P. Sympathetic skin response: normal results in different experimental conditions. ElectroencephClinNeurophysiol 1990; 76:258-267.

[17] Braune HJ. Early detection of diabetic neuropathy: a neurophysiological study on 100 patient. ElectromyogrClinNeurophysiol 1997; 37: 399-407.

[18] Aygül R, Ulvi H, Deniz O. NormallerdeSempatikDeriCevabiDalgaFormlar1, İnönüÜniversitesi Tıp FakültesiDergisi, 12[2] 77-82 [2005] . Turkish.

[19] Tokoyura M. Waveform and habituation of smypathetic skin response. ElectroencephClinNeurophysiol 1998; 109: $178-183$

[20] Vetrugno R, Liguori R, Cortelli P, Montagna P. Sympathetic skin response: basis mechanisms and clinical applications. ClinAuton Res. 2003; 13:256-270.

[21] Dumitru D, Zwarts MJ. Special Nerve Conduction Techniques. In: Dumitru D, Amato AA, Zwarts MJ, ed, Electrodiagnostic Medicine, $2^{\text {nd }}$ ed, Philadelphia, Hanley \&Belfus, Inc, 2002; 225-256.

[22] Ertekin C, Ertekin N, Mutlu S, Almis S, Akcam A. Skin potentials $[\mathrm{SP}]$ recorded from the extremities and genital regions in normal and impotent subjects. ActaNeurolScand 1987; 76: 28-36.

[23] Zhu GY, Shen Y. Sympathetic skin response: a new test to diagnose erectile dysfunction. Asia J Androl 2001 Mar; 3 [1]: 45-48.

[24] Chu NS. Recovery of sympathetic skin response after digit-to-digit replantation and toe-to-digit transplantation in humans. Ann Neurol 1996; 40: 67-74.

[25] Elie B, Guiheneuc P. Sympathetic skin response: normal result in different experimental condition ElectroencephalogrClinNeurophysiol. 1990; 76:258-267.

[26] Aydemir K. Reflekssempatikdistrofisendromlu el olgularındainvazive non-invaziv stellar ganglion blokajuygulamlarınıntens+egzersizterapisiilekarşılaştırıl masınınsempatikderiyanıtlarıyoluylaölçülmesi UzmanlıkTezi, Ankara 2004. Turkish.

[27] Akyüz G. OtonomSinirSistemiElektrofizyolojisi. Fiziksel Tip veRehabilitasyon, [Eds]Beyazova M, Kutsal Y., GüneşKitapevi Ltd. Şti. Ankara, cilt I, 560-569, 2000.

[28] Türkdoğan D, Akyüz Otonomsinirsistemielektrofizyolojisi. In: Akyüz G, Özaras N, Gündüz H, Ofluoğlu D, Elektrodiagnoz. 1 st ed. Ankara: Güneşkitapevi, 2003; 437-463. . Turkish. 
[29] Resende LAL, Matarazzo AT, Kimaid PAT, Silva MD Reconsideration about the clinical importance of the skin sympathetic response. ElectromyogrClinNeurophysiol 1997; 37: 463-468.

[30] Drory VE, Korczyn AD. Sympathetic skin response: Age effect. Neurology 1993; 43: 1818-1820.

[31] Baba M, Watahiki Y, Matsunaga M, Tabeke K. Sympathetic skin response in healty man. ElectromyogrClinNeurophysiol 1988; 28: 277-283.

[32] Macleod AF, Smith SA, Cowell T, Richardson PR, Sonksen PH. Non-cordiac autonomic test in diabetes: use of galvanic skin response. Diabetic Med 1991; 8 Symposium: S67-S70.

[33] Zakrzewska-Paniewska B, Kaminska A, KosteraPruszczyk A. Sympathetic skin response [SSR] in mutiple sclerosis. NeuroNeurochir Pol 1996; Supple 3: 121-128.

[34] Haapaniemi TH, Korpelainen JY, Tolonen U, Suominen K, Sotaniemi KA, Mylly VV. Suppressed smpathetic skin response in Parkinson disease. ClinAuton Res 200 Dec; 10 [6]: 337-342.

[35] Elie B, LouboutinJp. Sympathetic skin response [SSR] is abnormal in multiple sclerosis. Muscle Nerve 1995; 18: 185-189.

[36] Rossini PM, Massa R, Sancesairo G, Boccasena P. Sudomotor skin response to brain stimulation do not depend on nerve sensory fiber functionality. ElectroencephalogrClinNeurophysiol 1993; 89: 447-451.

[37] Rossini PM, Opsomer RJ, Boccasena P. Sudomotorskin response following nerve and brain stimulation. ElectroencephalogrClinNeurophysiol 1993; 89: 442-446.

[38] Linden D, Weng Y, Glocker FX, Kretzschmar A, Diehl RR, Berlit P. Sympathetic skin response evoked by magnetic stimulation of neck: normative data. Muscle Nerve 1996; 19: 1487-1489.

[39] Niehaus L, Meyer BU, Roricht S. Magnetic stimulation over different brain regions: no differential effects on the elicited sympathetic skin response. ElectroencephalogrClinNeurophysiol 1998; 109: 94-99.

[40] Toyokura M. Influence of stimulus intensity on waveform of sympathetic skin response evoked by magnetic stimulation. ClinNeurophysiol 2003 Aug; 114[8]: 1423-1430.

[41] Marcello N, Baratti M, Ortaggio F, Vescovini E, Zanoni P, Tugnoli V, De Grandis D. Sympathetic skin response in patients with Duchenne muscular dystrophy. ElectromyogrClinNeurophtsiol 1995; 35: 659-664.

[42] Rossi P, Truini A, Serrao M, Lannetti GD, Parisi L, Pozzessere G, Cruccu G. Sympathetic skin response evoked by laser skin stimulation. FunctNeurol 2002 JulSep; 17 [3]: 129-132.

[43] Cervera A, Veciana M, Valls-Sole J. Sympathetic sudomotor skin responses induced by laser stimuli in normal human subjects. NeurosciLett. 2002 Dec 13; 334 [2]: $115-118$

[44] Akyüz

ElektrodiagnozOtonomsinirsistemielektrofizyolojisi. 2003:437-463.

[45] Çakır

Inmelihastalardaelektromiyografiilereflekslerinvesempat kdericevabınınincelenmesivefonksiyonelkapasiteileilişki ninbelirlenmesi. UzmanlıkTezi. Afyonkarahisar 2008. Turkish.

[46] Yagiz A, Colakoglu Z, Hepguler S, Aksit R. Local heat effect on sympathetic skin response after pain of electrical stimulus. Arch Phys Med Rehabil 1997; 78: 1196-1199.
[47] Deltombe T, Hanson P, Jamart J, Clerin M. The influence of skin temperature on latency and amplitude of the sympathetic skin response in normal subjects.

[48] Maulsby RL, Edelberg R. The interrelationship between the galvanic skin responce, basal resistance, and tempature. J Comp Physiol Psychol. 1960;53:475-9.

[49] Yokota T, Takahashi T, Kondo M Fujimori B. Studies on the diphasic wave form of the galvanic skin reflex. ElectroencephalogrClinNeuropysiol. 1959;11:687-696.

[50] Uncini A, Pullnan SL, Lovelace RE, Gambi D. The sympathetic skin response normal values, elucidation of afferent components and applicantion limits. J NeurolSci 1988; 87: 299-306.

[51] Gutrecht JA. Sympathetic skin response. J ClinNeurophysiol 1994; 11 [5]: 519-524.

[52] Raszewa M. Hausmanova-Petrusewicz I, Blaszczyk M, jablonska S. Sympathetic skin response in scleroderma. ElectromyogrClinNeurophysiol 1991; 131: 467-472.

[53] Miscio G, Pisano F. Sympathetic skin response in amyotrophic lateral sclerosis. ActaNeurolScand 1998; 98: 276-279.

[54] Lin TK, Chee EC, Chen HJ, Cheng MH. Abnormal sympathetic skin response, n patient with palmar hyperhidrosis. Muscle Nerve 1995; 18: 917-919.

[55] Milanlığlu A, Tombul T, Sayın R. Sympathetic skin response in migraineurs, Journal of Clinical and Experimental Invegtigations 2011; 2 [1]: 16-21.

[56] Neuman E, Blanton R. The early history electrodermal research. Psychophysiology 1970; 6:453-475.

[57] Kula H. Egzersizinsporcularda elektrodermal aktiviteüzerineetkisi. YüksekLisansTezi, Kayseri 2006 Turkish.

[58] Boucsein W. Electrodermal Activity. New York, Plenum Press, 1992: 1-372.

[59] Schmind S, Walach H. Electrodermal activity [EDA]state of the art measurement and techniques for parapsychological purposes. The Journal of parapsychology 2000; 64: 139-163.

[60] Schmidt S, Schneider R, Binder M, Burkle D \&Walach $\mathrm{H}$. Investigating methodological issues in EDA DMILS: Results from a pilot study. The Journal of Parapsychology 2001; 65:59-82.

[61] Zakrzewska-Pniewska B, Jamrozik Z. Are electrophysiological autonomic tests useful in the assessment of dysautonomia in Parkinson's disease? Parkinsonism Rel D 2002; 9[3]:179.

[62] Yıldız SK, Türkoğlu ŞA, Yıldız N, Öztürk A, Töre F: Sympathetic skin responses of the face and neck evoked by electrical stimulation Autonomic Neuroscience: Basic and Clinical 134 [2007] 85-91.

[63] Özkan Ö, Yildiz M, Köklükaya E. "Fibromiyalji sendromununteşhisindekullanılanlaboratuartestlerininse mpatikdericevabıparametreleriyledesteklenerekteşhisdoğ ruluğununarttırılması", SAÜ. Fen BilimleriDergisi, 15 Cilt, 1. Sayı, s.1-7, 2011. Turkish.

[64] Boel RefleksSempatikDistrofiSendromluOlgulardaSempatikD eriYanıtları. UzmanlıkTezi, Sivas 1999. Turkish.

[65] Doğramacı AÇ, Okuyucu EE. Sympathetic skin response in patient with vitiligo, Turkderm-Archives of the Turkish Dermatology and Venerology, 2009; 43: 58-60.

[66] Çakır T, Evcik D, Dündar Ü, Yiğit İ, Kavuncu V. Evaluation of sympathetic skin response and $\mathrm{F}$ wave in fibromyalgia syndrome patient, Turk $\mathrm{J}$ Rheumatol 2011;26[1]:38-43 doi: 10.5606/tjr.2011.006. Turkish. 